\title{
Mapping Buried Alluvial Layer Using Integrated Seismic Refraction and 2-D Resistivity Inversions at Sungai Batu, Kedah, Malaysia
}

\author{
Rais Yusoh, ${ }^{1}$ Najmiah Rosli, ${ }^{1}$ Nazrin Rahman, ${ }^{1}$ Rosli Saad ${ }^{1 *}$ and Mokhtar Saidin ${ }^{2 * *}$ \\ ${ }^{1}$ Geophysics Section, School of Physics, Universiti Sains Malaysia, \\ 11800 USM Pulau Pinang, Malaysia \\ ${ }^{2}$ Centre for Global Archaeological Research, Universiti Sains Malaysia, \\ 11800 USM Pulau Pinang, Malaysia \\ Corresponding authors: rosli28260@gmail.com," mmokh@usm.my**
}

Published online: 25 April 2020

To cite this article: Yusoh, R. et al. (2020). Mapping buried alluvial layer using integrated seismic refraction and 2-D resistivity inversions at Sungai Batu, Kedah, Malaysia. J. Phys. Sci., 31(1), 121-128. https://doi.org/10.21315/jps2020.31.1.8

To link to this article: https://doi.org/10.21315/jps2020.31.1.8

\begin{abstract}
Resistivity and seismic refraction are conventional methods in preinvestigations of subsurface structures, which are commonly employed and interpreted separately to reduce ambiguities from each method. Although integration of the two methods' models into a single model was recently introduced, the integration still requires enhancement to generate an accurate subsurface profile. Therefore, an enhanced algorithm called closure coupling technique was developed to integrate 2-dimensional (2-D) models of resistivity and seismic refraction to become a single integrated model where one model influences the other model. The resultant integrated model is superior in mapping the subsurface compared with singular resistivity and seismic models. These methods were then applied on a pre-investigative field dataset in finding ancient river for archaeological point of interest. Due to complex geology, only slight changes were observed in the inverted model of the integrated data inversion for this archetype. Still, the combined model enhanced subsurface interpretation by highlighting the distribution of buried alluvial soil.
\end{abstract}

Keywords: Seismic refraction, 2-D resistivity, Lembah Bujang, combined inversion, Sungai Batu 


\section{INTRODUCTION}

Mapping of subsurface profile is a critical part in any site investigation which is the reason geophysical surveys, including resistivity and seismic methods, play an important role as they are capable in mapping a region without harming the environment. ${ }^{1}$ This paper intends to integrate resistivity and seismic refraction methods to reduce the ambiguity inherent from both methods. While each method is a powerful subsurface-mapping tool, they do have limitations such as overlapping range of resistivity values of different materials such as clay and shale, but in this case, the materials could be differentiated using seismic refraction method due to different density of the materials. ${ }^{2}$ In contrast, when the higher density upper subsurface layer is underlain by a lower density layer, seismic refraction method cannot distinguish the between the two layers but these layers could be distinguished by resistivity method. ${ }^{3}$ A way to play around the limitations is by combining inversion data from both methods via closure coupling to generate an enhanced model where one model influences the other model.

Even though geophysical inversion for both resistivity and seismic refraction methods can be easily done by conventional software packages, restrictions still exist in combining the two inverted models into a single 2-dimensional (2-D) section. ${ }^{4}$ With this in mind, this research aimed to design an algorithm to integrate the inverted models using MS Excel software by tying the models based on same coordination of data point to improve geological interpretation and then to evaluate the viability of this technique.

\section{EXPERIMENTAL}

\subsection{Study Area}

The study area is situated at Sungai Batu, a well-known ongoing archaeological investigation site in Lembah Bujang district near Merbok in Kedah, northwest Peninsular Malaysia. ${ }^{5}$ Sungai Batu area is also in close proximity to Gunung Jerai (Mount Jerai) and Sungai Merbok (Merbok River) as it is a subsidiary of the water channel. Gunung Jerai is made up of two rock types which are sedimentary rocks and granite (western region). Gunung Jerai sedimentary rock is made of sandstone or metasandstone with a mixture of siltstone, shale and minor conglomerate, which were formed during Cambrian Age. Mid-south of Kedah was documented to be fully submerged by transgressing sea level during the first and second centuries. By the 15th century, the area became flat and dry of sea water since the previous water rise. ${ }^{6}$ These sea level underwent changes throughout the centuries causing the present area to be covered with marine sandy clay and fine sand. Some of the 
sediments were also deposited onto the area from the river flow. Up until now, the topography of the study area remains flat with fertile soil to give way for palm and rubber plantations. Due to close proximity to both sea and large water channel (Sungai Merbok), several swamps and small distributary rivers are located in the eastern part of the study area.

\subsection{Data Acquisition}

Seismic refraction was acquired using ABEM Terraloc with a constant spacing of $5 \mathrm{~m}$ between geophones whereas resistivity data was obtained using ABEM Terrameter SAS4000 at the same spacing distance as seismic method. Coordinates of each datum point were taken using global positioning system (GPS) for ground corrections. One survey line from each method was designed to cut across a borehole (BH1) as portrayed in Figure 1, where borehole data was used as a supplementary data to support geophysical data. The length of each survey line is $200 \mathrm{~m}$. For seismic refraction method, a sledge hammer was employed as the seismic source where a total of seven shot points was carried out; five shots were in-line shots while two were offset shots and the seismic signals were picked up by the 24 geophones laid along the survey line. Meanwhile, resistivity survey was conducted using 41 electrodes with pole-dipole array along the same line as seismic method.

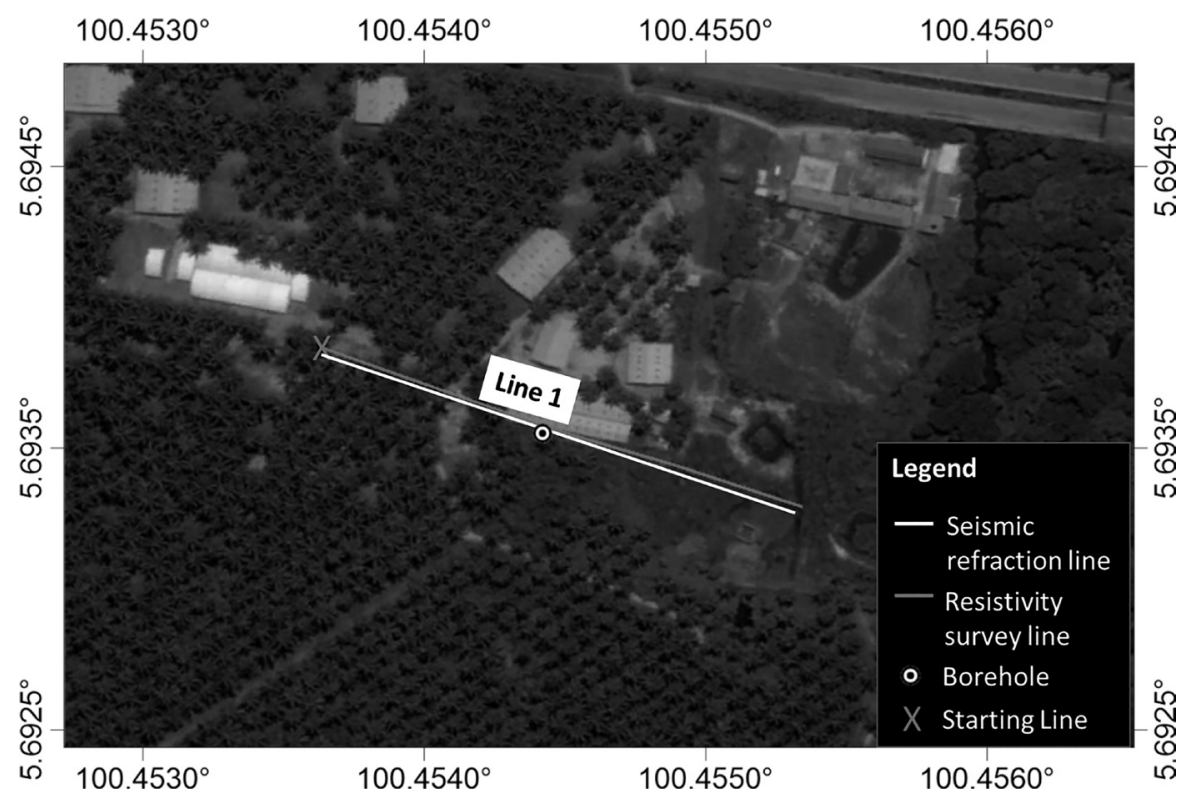

Figure 1: Seismic refraction and electrical resistivity survey lines at Sungai Batu, Lembah Bujang, Kedah. 


\subsection{Inversion}

Seismic refraction and resistivity models were produced individually by inversion of data measured from field data acquisition. ${ }^{7}$ For seismic refraction, various interpretation techniques are available such as first break technique. ${ }^{8-10}$ First break interpretation technique is commonly utilised for small-scaled refraction surveys where the wanted seismic refraction signals are analysed in terms of their amplitude and arrival times to generate time sections in a full trace processing. ${ }^{11}$

FirstPix (version 4.21) and SeisOpt@2D (version 3.5) software programs were used to analyse the seismic refraction data. FirstPix software was used to pick the first arrival time of each seismic trace before generating an initial velocity model. This step was followed by iteratively tracing the rays through the model in order to compare the calculated travel times with the measured travel times, during which the model kept modifying in each iteration until the minimum amount of difference between calculated and measured times was achieved. ${ }^{11}$ From this inversion model, SeisOpt@2D software was then employed using the previously processed data to visualise the subsurface section via tomography modelling.

On the contrary, the entire process of generating resistivity inversion model was done using RES2DINV program. Smoothness-constrained Gauss Newton least squares inversion method was chosen in RES2DINV to create a 2-D true resistivity model from apparent resistivity data. ${ }^{12}$ Optimum inversion cycle was automatically iterated by the program but can be modified manually based on inversion parameters.

\section{RESULTS AND DISCUSSIONS}

The results obtained from seismic refraction and resistivity surveys are presented in 2-D section images after undergoing inversion processes as illustrated in Figure 2. The seismic refraction image shown in Figure 2(a) is based on compressional wave velocities values, $\mathrm{V}_{\mathrm{p}}\left(\mathrm{m} \mathrm{s}^{-1}\right)$ while resistivity image in Figure 2(b) is based on resistivity inversion values, $\rho$ (ohm.m). Lithology profile obtained from borehole B1 as in Figure 2(c) was also taken into consideration during interpretation of the subsurface for alluvial layer mapping. 


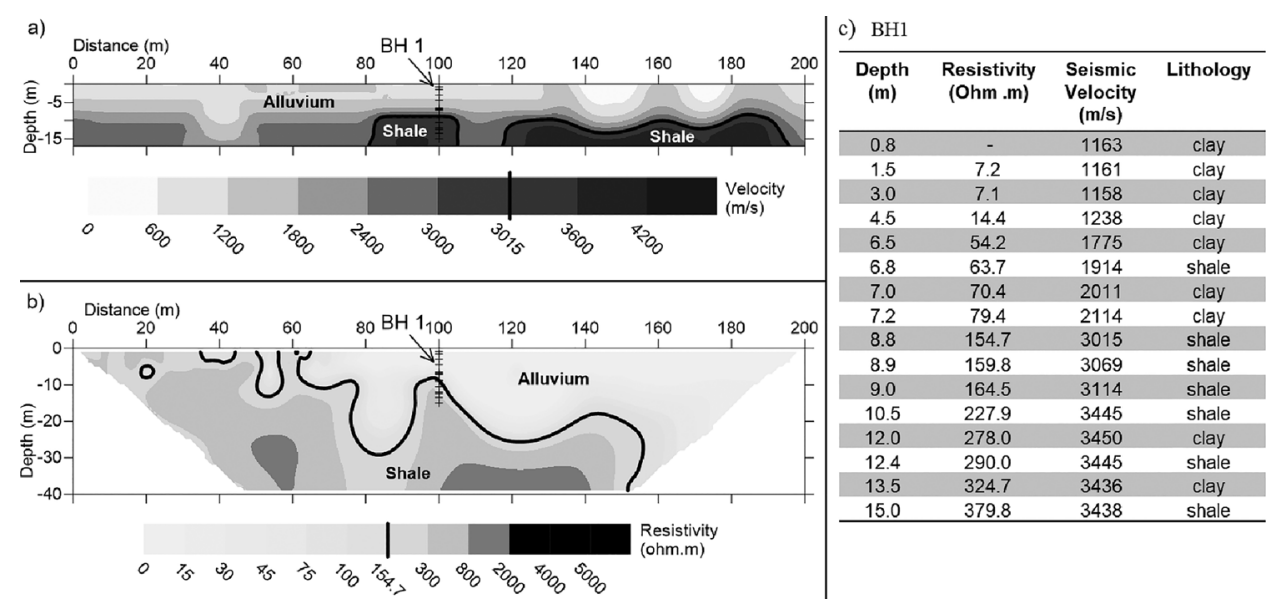

Figure 2: 2-D pseudo-section image of (a) seismic refraction, (b) electrical resistivity, and (c) lithology profile compared with resistivity and seismic velocity values.

Figure 2(a) shows the seismic refraction image where the overall velocity ranges for $1-4200 \mathrm{~m} \mathrm{~s}^{-1}$. Taking into account the geology of the study area, two types of lithologies, namely alluvial soil and shale stone, could be distinguished from both geophysical results and borehole information. Alluvial soil is physically different from shale as shale is rock, and therefore has greater density and strength compared to alluvium. This difference could be observed in seismic section where shale has higher velocity of 3015-3445 $\mathrm{m} \mathrm{s}^{-1}$ compared to alluvium which has velocity values of $<3015 \mathrm{~m} \mathrm{~s}^{-1}$. This implies that the alluvial soil in the area is located at depths of 0-9 $\mathrm{m}$ from ground surface while shale underlies the soil at depths of $10-40 \mathrm{~m}$.

By observing the electrical resistivity image in Figure 2(b), it can be concluded that resistivity in the area has the highest value of $5000 \mathrm{ohm} . \mathrm{m}$ and the lowest value of 1 ohm.m due to difference in the subsurface lithologies, primarily. By correlating the resistivity image with borehole record, the shale was denoted to lie within the resistivity values of $154.7-379.8 \mathrm{ohm} . \mathrm{m}$ while the alluvial layer has resistivity values of $<154.7$ ohm.m. At a glance, both seismic refraction and resistivity image sections did not produce subsurface patterns that are similar even though the surveys were conducted on the same line. This is due to the fact that both methods measure different physical properties of the subsurface; thus emphasising that each method has different strengths and weaknesses in interpreting the geological aspect which could be utilised to full potential by integrating the geophysical data into a single image section. 
Using the individual inversion data from the two geophysical surveys, the integrated inversion section is depicted in Figure 3 in the form of 2-D model based on four different classes of geophysical characteristics at Sungai Batu archaeological site. The number of classes was classified with regards to both resistivity and seismic refraction data while concurrently correlating with lithology profile. Classes 1 and 2, which primarily consist of alluvial soil, have velocity values of $<3015 \mathrm{~m} \mathrm{~s}^{-1}$ but different resistivity values that could be attributed to variation of moisture content. The first class has lower resistivity values of $<154.7 \mathrm{ohm}$.m while the second class has values of $\geq 154.7 \mathrm{ohm}$.m. From this, it could be seen that the alluvial layer has a thickness of roughly 4-15 $\mathrm{m}$ along the survey line. Classes 3 and 4 are categorised as shale due to higher seismic values $\left(>3015 \mathrm{~m} \mathrm{~s}^{-1}\right)$ where Class 3 consists of resistivity values of $<154.7$ ohm.m. With higher resistivity values ( $\geq 154.7$ ohm.m), Class 4 might have lower moisture content or less weathered than Class 3.

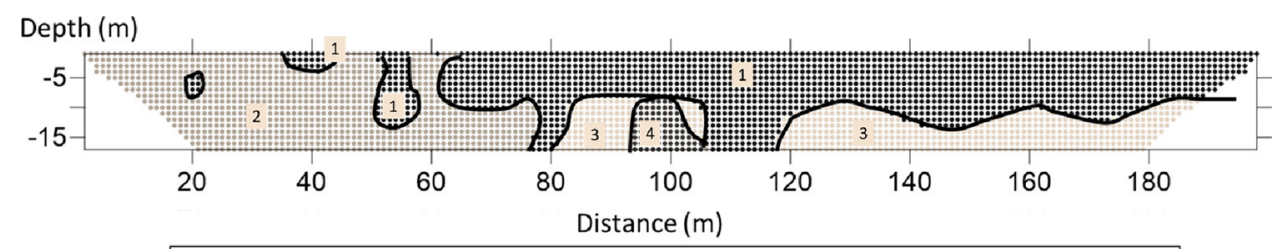

\begin{tabular}{|l} 
Legend \\
Class 1: Low resistivity $(<154.7 \mathrm{ohm} . \mathrm{m})$ with low seismic velocity $\left(<3015 \mathrm{~m} \mathrm{~s}^{-1}\right)$ \\
Class 2: High resistivity $(\geq 154.7 \mathrm{ohm} . \mathrm{m})$ with low seismic velocity $\left(<3015 \mathrm{~m} \mathrm{~s}^{-1}\right)$ \\
Class 3: Low resistivity $(<154.7 \mathrm{ohm} . \mathrm{m})$ with high seismic velocity $\left(\geq 3015 \mathrm{~m} \mathrm{~s}^{-1}\right)$ \\
Class 4: High resistivity $(\geq 154.7 \mathrm{ohm} . \mathrm{m})$ with high seismic velocity $\left(\geq 3015 \mathrm{~m} \mathrm{~s}^{-1}\right)$
\end{tabular}

Figure 3: Combined inversion class model derived from seismic refraction and electrical resistivity, depicting four classes.

A total of 3240 synchronised data were used in combining the two geophysical data by class derived from both seismic refraction and resistivity inversion results. Figure 4 illustrates four classes sorted by cross-plotting in a graph of seismic velocities against resistivity values. Classes 1 and 2 are larger than the other classes with 871 and 1528 data points, respectively. Class 1 dominates the survey profile as it takes up almost half of the total data point (47.16\%). It is also worthy to note the horizontal changes (from top to bottom layers) in the integrated section which is suspected to be due to the geological setting (sedimentary) of the alluvium-rich study area is predominantly found near the surface. The integrated section generated from this technique eases geological interpretation processes as it enhances the targeted material for better visualisation. 


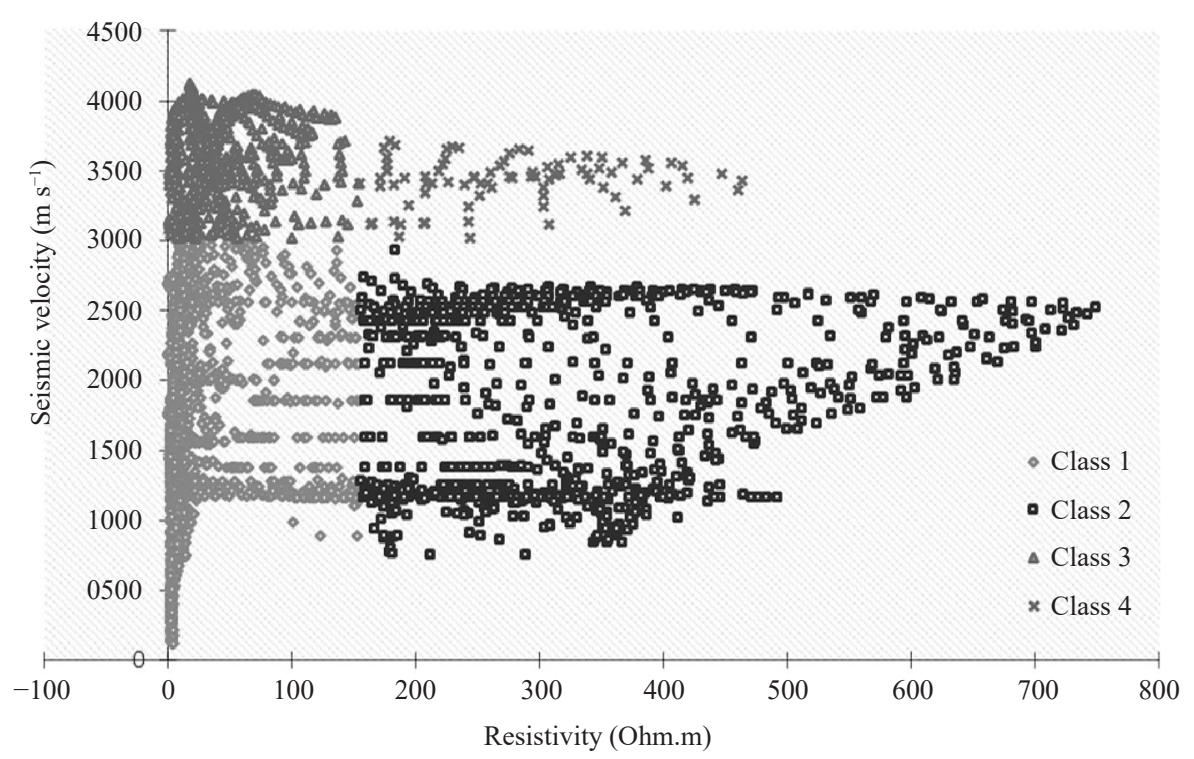

Figure 4: Illustration of cross-plot of seismic velocity and resistivity values from combined inversion.

\section{CONCLUSION}

Combined inversions in this study case is obviously beneficial as the new section enhances the targeted layer, which is the alluvial layer, setting it apart from the rest of the subsurface layers. The class-separation analysis produces an additional mechanism for interpretation while simultaneously highlighting the alluvial soil for ancient river exploration in archaeological investigation. With this integration technique, any ambiguities from one geophysical method are supported by the other method, thus dramatically increasing data interpretation accuracy while concurrently making data interpretation much easier. This demonstrates that integration of inversion analysis has high potential for future geophysical analyses development.

\section{ACKNOWLEDGEMENTS}

This research was supported by Universitti Sains Malaysia (USM) through grant "Verification of Penarikan Route by Archaeological Data Perspective at Sungai Muda, Kedah, Malaysia" (grant no. 1001/PARKEO/8016061). Gratitude is further extended to USM geophysics staff and postgraduate students for their time and effort during data acquisition. 


\section{REFERENCES}

1. Razak, A. F., Said, M. A. M. \& Yusoh, R. (2015). Riverbank filtration site suitability selection using spatial data techniques: Case study for Kota Lama Kiri, Kuala Kangsar, Appl. Mech. Mater., 802, 557-562. https://doi.org/10.4028/www. scientific.net/AMM.802.557

2. Hamada, G. M., Al-Blehed, M. S. \& Al-Awad, M. N. (2000). Nuclear magnetic resonance $\log$ evaluation of low-resistivity sandstone reservoirs by-passed by conventional logging analysis. Paper presented at the SPE Asia Pacific Oil and Gas Conference Exhibition, 16-18 October, Brisbane. https://doi. org/10.2118/64406-MS

3. Hellman, K., Günther, T. \& Dahlin, T. (2012). Application of joint inversion and fuzzy c-means cluster analysis for road pre-investigations. Paper presented at the 18th European Meeting of Environmental and Engineering Geophysics, Paris, 3-5 September. https://doi.org/10.3997/2214-4609.20143417

4. Azwin, I. N. et al. (2015). Combined analysis of 2-D electrical resistivity, seismic refraction and geotechnical investigations for Bukit Bunuh complex crater. IOP Conf. Ser. Earth Environ. Sci., 23(1), 012013. https://doi.org/10.1088/1755$1315 / 23 / 1 / 012013$.

5. Saad, R. et al. (2015). Identifying Sungai Batu ancient river by magnetic method. Electron. J. Geotech. Eng., 20(18), 11143-11148.

6. De Casparis, J. G. (1964). The Golden Khersonese: Studies in the historical geography of the Malay Peninsula before AD 1500. J. South. Asian Hist., 5(1), 222-224. https://doi.org/10.1017/S0217781100002398

7. Kearey, P., Brooks, M. \& Hill, I. (2013). An introduction to geophysical exploration. New York: John Wiley \& Sons.

8. Hales, F. W. (1958). An accurate graphical method for interpreting seismic refraction lines. Geophys. Prospect., 6, 285-294. https://doi.org/10.1111/j.1365-2478.1958. tb01655.x

9. Hagedoorn, J. G. (1959). The plus-minus method of interpreting seismic refraction sections. Geophys.Prospect., 7,158-182.https://doi.org/10.1111/j.1365-2478.1959. tb01460.x

10. Palmer, D. (1980). The generalized reciprocal method of seismic refraction interpretation. New York: Society of Exploration Geophysics.

11. Wei, W. et al. (2016). Seismic exploration in complex near-surface and foothills regions - A case study from northwest of the Tarim basin. Paper presented at the SPG/SEG International Geophysical Conference, Beijing, 20-22, 295-298. https://doi.org/10.1190/IGCBeijing2016-085

12. Sasaki, Y. 1992. Resolution of resistivity tomography inferred from numerical simulation. Geophys. Prospect., 40, 453-464. https://doi. org/10.1111/j.1365-2478.1992.tb00536.x 